\title{
Low Grade Central Mucoepidermoid Carcinoma
}

\author{
1Janaki Subramanian Iyer, ${ }^{2}$ Kartik Poonja, ${ }^{3}$ Jigna Pathak, ${ }^{4}$ Shilpa Patel, ${ }^{5}$ Leela Poonja
}

\begin{abstract}
Mucoepidermoid carcinoma (MEC) is the most common malignant salivary gland tumor, comprising about $15 \%$ of all salivary gland tumors and $30 \%$ of all salivary malignancies. Most of the MEC arise in the parotid gland. Rarely, it originates in the mandible and maxilla as an intraosseous variant, referred to as 'central mucoepidermoid carcinoma' or 'intraosseous mucoepidermoid carcinoma'. Central mucoepidermoid carcinomas (CMECs) are extremely rare, but well-known entity, comprising 2 to $3 \%$ of all MECs reported. Histopathologically, this malignant neoplasm is characterized by mucous, intermediate and epidermoid cells. In this report, we present a case of a male patient diagnosed as low grade CMEC.
\end{abstract}

Keywords: Central mucoepidermoid carcinoma, Intraosseous, Mandible, Low grade.

How to cite this article: lyer JS, Poonja K, Pathak J, Patel S, Poonja L. Low Grade Central Mucoepidermoid Carcinoma. J Contemp Dent 2015;5(1):31-34.

Source of support: Nil

Conflict of interest: None

\section{INTRODUCTION}

Mucoepidermoid carcinoma (MEC) is the most common malignant salivary gland tumor, comprising about $15 \%$ of all salivary gland tumors and $30 \%$ of all salivary malignancies. ${ }^{1}$ This entity was initially proposed by Masson and Berger in 1924. ${ }^{2}$ Stewart et al, in 1945, described its mucus secreting and epidermal cellular elements, thus, establishing it as a distinct pathologic entity. ${ }^{3}$ The involvement of parotid glands predominate, representing $45 \%{ }^{4}$ Palate is the most frequently involved minor salivary gland site. ${ }^{3}$ Mucoepidermoid carcinoma can also arise from ectopic salivary gland tissue in periparotid lymph nodes as well as in the larynx, lacrimal gland, nose, paranasal sinuses, lung and trachea. Rarely, it originates in the mandible and maxilla as an intraosseous

\footnotetext{
${ }^{1}$ Postgraduate Student, ${ }^{2}$ Lecturer, ${ }^{3,5}$ Professor

${ }^{4}$ Professor and Head

1,3-5 Department of Oral Pathology and Microbiology, MGM Dental College and Hospital, Navi Mumbai, Maharashtra, India

${ }^{2}$ Department of Oral and Maxillofacial Surgery, MGM Dental College and Hospital, Navi Mumbai, Maharashtra, India
}

Corresponding Author: Janaki Subramanian lyer, Postgraduate Student, Department of Oral Pathology and Microbiology, MGM Dental College and Hospital, Navi Mumbai, Maharashtra, India Phone: 9869040237, e-mail: drjanakisiyer@gmail.com variant, referred to as 'central mucoepidermoid carcinoma (CMEC)' or 'intraosseous mucoepidermoid carcinoma'. ${ }^{3}$ Central mucoepidermoid carcinomas are extremely rare, but a well-known entity, comprising 2 to $3 \%$ of all MECs reported. ${ }^{5}$ Lepp in 1939 first reported of a CMEC of the mandible in a 66-year-old woman, and Bhaskar (1963) analyzed the criteria for their central origin, histology and pathogenesis. ${ }^{6}$ Waldron and Mustoe (1989) suggested that CMEC should be included in primary intraosseous carcinoma of jaws as type $4 .^{7}$

Classification of primary intraosseous carcinomas (Waldron and Mustoe) ${ }^{7}$ is as follows:

- Type 1: Primary intraosseous odontogenic carcinoma ex odontogenic cyst

- Type 2A: Malignant ameloblastoma

- Type 2B: Ameloblastic carcinoma

- Type 3: Primary intraosseous odontogenic carcinoma developed de novo
a. Keratinizing type
b. Nonkeratinizing type

- Type 4: Central intraosseous mucoepidermoid carcinoma

Mucoepidermoid carcinoma is defined by WHO (2005) as a malignant glandular epithelial neoplasm characterized by mucous, intermediate and epidermoid cells, with columnar, clear cell and oncocytoid features. ${ }^{4}$ Previous literature indicates over 150 reported cases of CMEC. Here, we report a case of a 27-year-old male patient with a chief complaint of painful slow-growing swelling on left posterior aspect of lower jaw diagnosed as low grade CMEC.

\section{CASE REPORT}

\section{Clinical and Radiographic Features}

A 27-year-old male patient reported to the Department of Oral and Maxillofacial Surgery, Mahatma Gandhi Missions Dental College and Hospital, with a complaint of tender, slow-growing swelling on the left posterior region of lower jaw since 2 months. He gave history of dull, continuous pain related to fully erupted 38 which gradually increased over 2 months. He was advised extraction of 38 by a general dental physician. Patient noticed subsequent increase in pain postextraction, with no change in swelling. He gave no history of consumption of any deleterious substances. Extraoral clinical examination revealed a diffused, tender, nonfluctuant, noncompressible and nonreducible swelling measuring 
around $3 \times 2 \mathrm{~cm}$ on left mandibular body extending posteriorly to the angle of the mandible (Fig. 1). Oral examination disclosed an incompletely healed, tender extraction socket of 38, with no other significant findings (Fig. 2). Left submandibular lymph nodes were palpable and tender, and no signs of paresthesia were evident. His medical and family history was not contributory.

Orthopantomograph revealed an ill-defined unilocular radiolucency in the left body of the mandible extending from the distal root of 37 to the angle of the mandible and till the lower border of the mandible inferiorly. Resorption of the distal root of 37 and the extraction socket of 38 were also evident (Fig. 3).

Clinical and radiological differential diagnosis included cyst or tumor of odontogenic origin. An incisional biopsy was performed, after obtaining consent.

\section{Histopathological Features}

Histopathologically, the hematoxylin and eosin-stained soft-tissue section showed small and large closely packed nests of epidermoid, intermediate and mucous cells in a fibrous connective tissue stroma (Figs $4 \mathrm{~A}$ and B). The mucous cells of varied shapes and sizes had abundant pale foamy cytoplasm. Epidermoid cells were polygonal in shape with ovoid to elongated nuclei and abundant eosinophilic cytoplasm. Areas of microcyst formation (Fig. 5) and focal areas of clear cells were also evident. Normal mucous acini and lymphoid aggregates were seen in the vicinity of the lesional tissue. The histopathological features were suggestive of low grade variant of CMEC. Alcian blue staining performed indicated positive mucous cell population (Fig. 6).

\section{DISCUSSION}

Aberrant salivary gland tissue may be found in numerous regions of the body to include lymph nodes, ear, thyroglossal duct and pituitary gland. However, central salivary gland tumors are extremely rare. Central mucoepidermoid carcinoma tend to affect the mandible (premolar-molar region) thrice more than the maxilla, with majority of the cases occurring in 4 th to 5 th decades of life. ${ }^{8}$ Generally, main presented symptoms are swelling with bony expansion, in posterior mandible with or without paresthesia. ${ }^{6}$ Our case, though presenting with intraosseous swelling involving the posterior mandible, was in a male patient of age 27 years.

The diagnostic criteria for CMEC were laid down by Alexander in 1974, later modified by Browand and Waldron in 1975 which included the following:9,10

- Intact cortical plate

- Radiological evidence of bone destruction

- Histologic confirmation

- Positive mucin staining
- Absence of primary lesion in salivary gland

- Exclusion of an odontogenic tumor

- Our case fulfilled the diagnostic criteria for CMEC that was laid down by them.

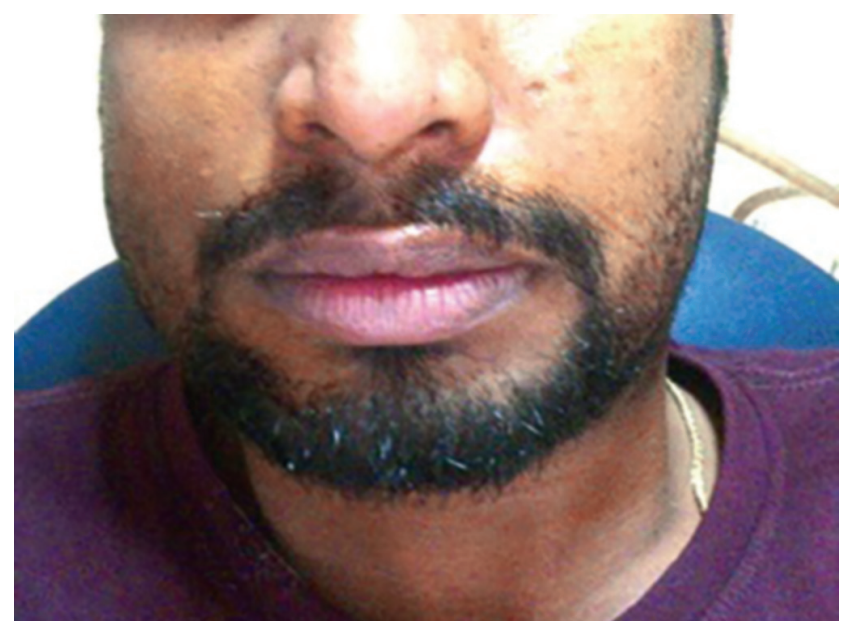

Fig. 1: Extraoral view showing a diffuse swelling on left mandibular body extending posteriorly to the angle of the mandible

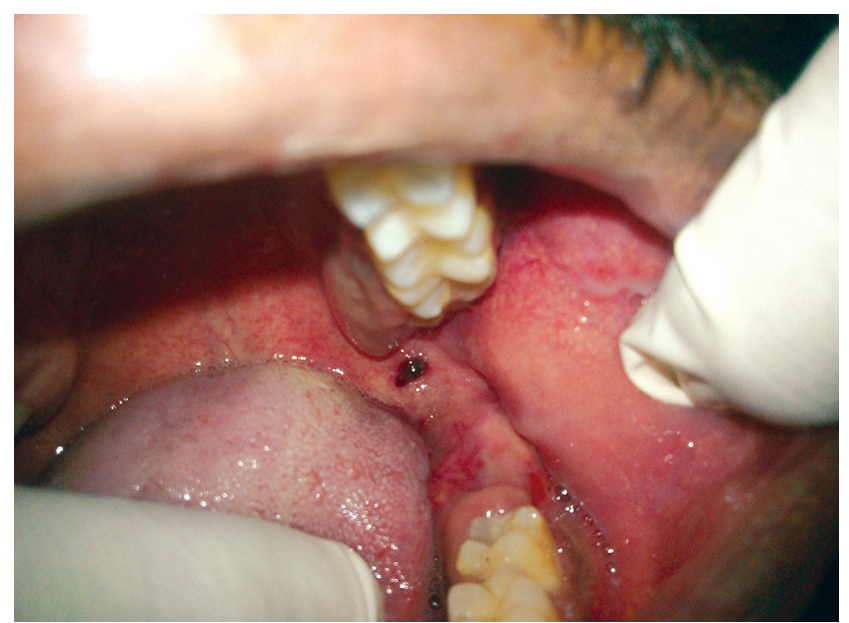

Fig. 2: Intraoral view revealed an incompletely healed extraction socket of 38 with bicortical expansion

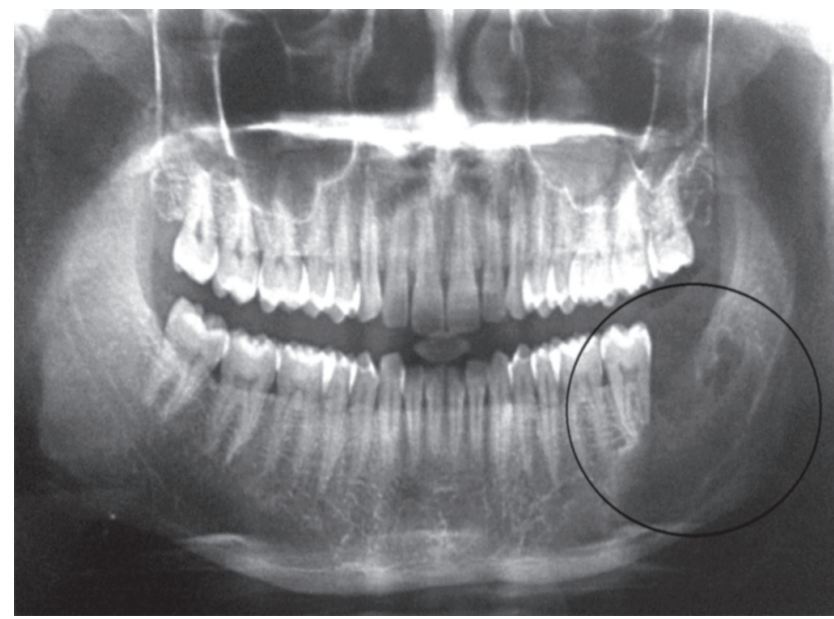

Fig. 3: Orthopantomograph revealed an ill-defined unilocular radiolucency in the left body of the mandible extending from the resorbed distal root of 37 to the angle of the mandible and inferiorly to the lower border of the mandible 

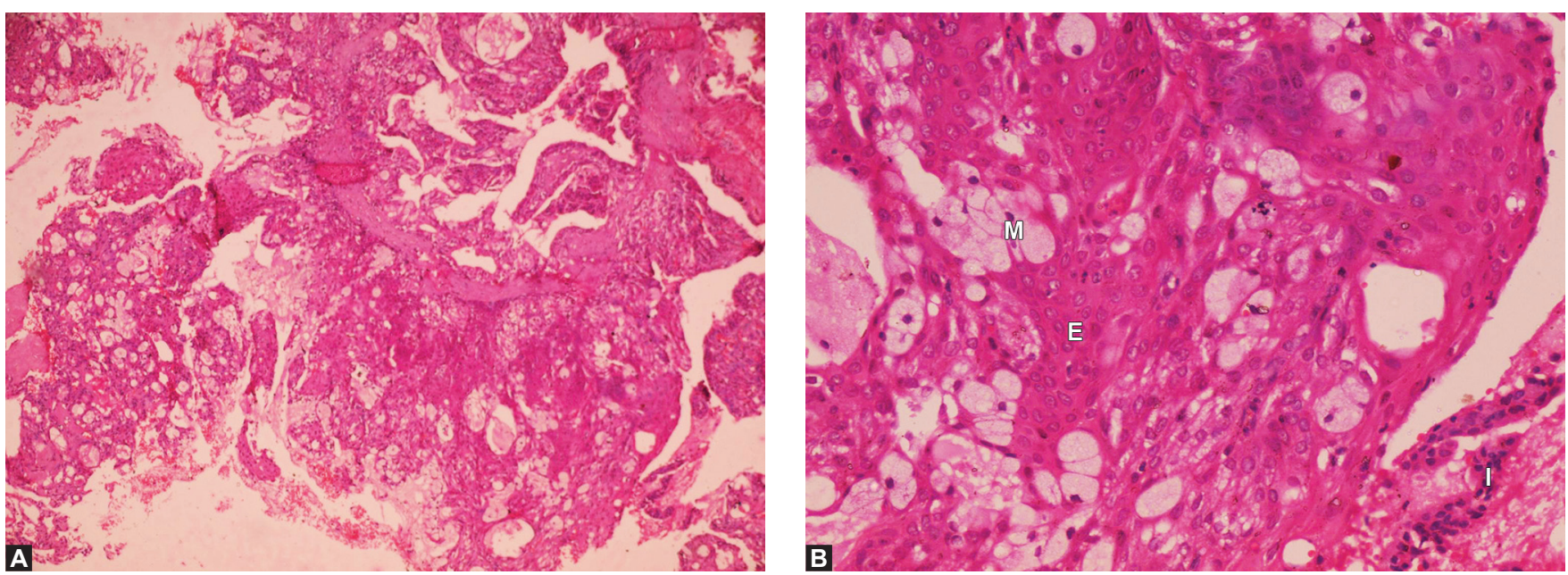

Figs 4A and B: (A) Small and large closely packed nests of epidermoid, intermediate and mucous cells in a fibrous connective tissue stroma. Areas of cystic degeneration also evident (H\&E: 100x), (B) tumor islands composed of epidermoid (E), intermediate (I) and mucous (M) cells in a fibrous connective tissue stroma (H\&E: 400x)

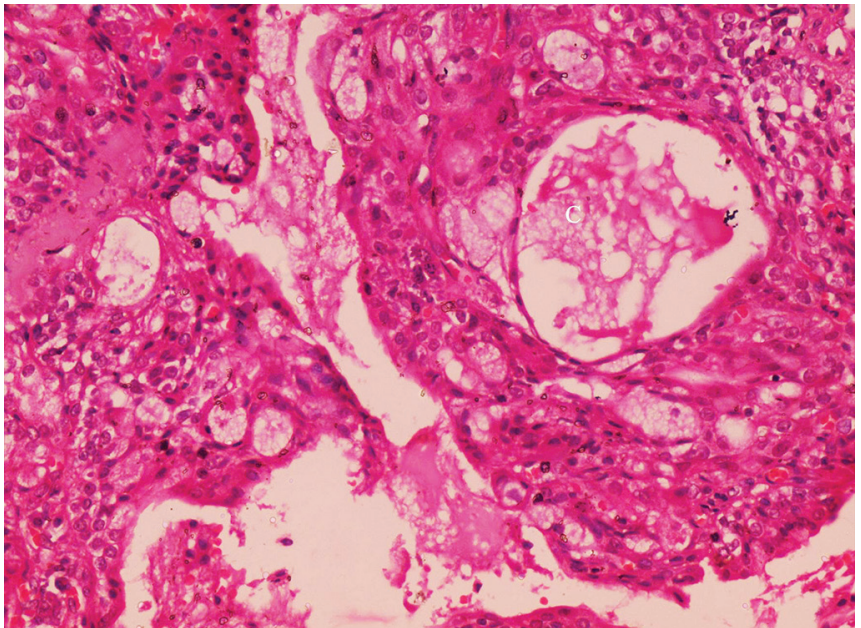

Fig. 5: Tumor islands showing areas of microcyst formation (C) (H\&E: 400x)

Brookstone and Huvos et al in 1992 proposed a staging system based on the condition of the overlying bone. $^{5}$

- Stage I: Lesions with intact cortical plates with no evidence of bone expansion.

- Stage II: Tumors with intact plates but intraosseous expansion.

- Stage III: Lesions associated with cortical perforation or nodal disease.

Our case was in staged II, due to intact cortical plates with evident bony expansion.

The origin of CMEC is still controversial and some theories have been introduced, including: ${ }^{11}$

- Ectopic salivary glands tissue that was developmentally entrapped in the jaws.

- Neoplastic transformation of the sinus epithelium.

- Neoplastic transformation of the epithelial lining of an odontogenic cyst (especially dentigerous cysts).

Eversole et al found that approximately $50 \%$ of mandibular CMEC were associated with dental cysts or

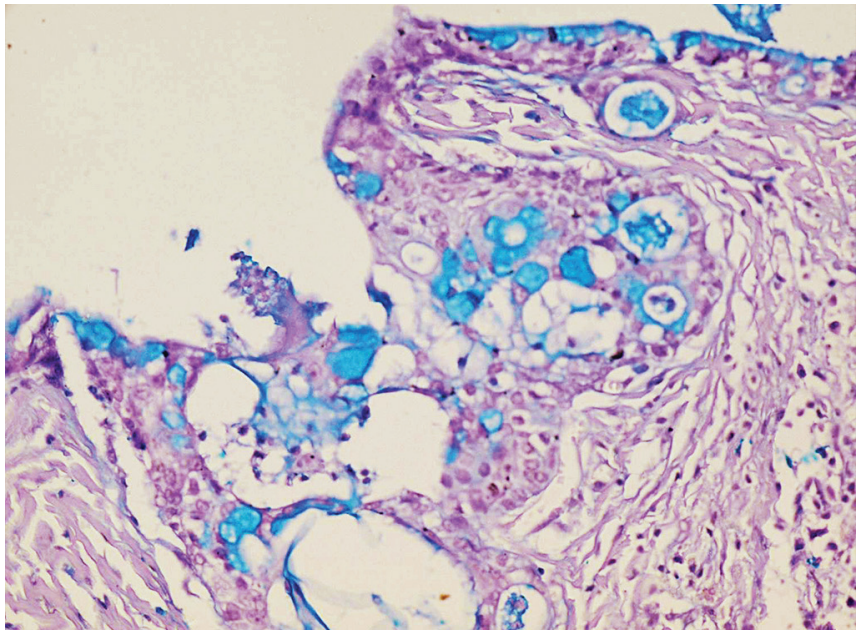

Fig. 6: Alcian blue positive mucous cell population (alcian blue: $400 x$ )

impacted teeth, whereas Brookstone and Huvos report a rate closer to $32 \%{ }^{11}$

Mucoepidermoid carcinoma is thought to arise from pluripotent reserve cells of the excretory ducts of salivary gland that have the potential to differentiate into squamous, columnar and mucous cells. ${ }^{2,4}$ Microscopically, these tumors are characterized by the presence of two populations of cells-the mucus cells and the epidermoid cells, the proportion of which helps to define the grade of the tumor. The epidermoid cells are most easily detected by its appearance. Mucous cells may contain microscopic granules filled with acid mucopolysaccharide, which yield the appearance of foam cells or goblet

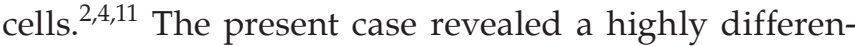
tiated neoplasia with a predominance of microcysts and presence of mucin-producing cells. Special staining for mucicarmine or alcian blue can readily identify the mucous cell population, which is considered diagnostic since mucous cells are only rarely encountered in other salivary tumors. ${ }^{5}$ Our case revealed alcian blue positive 
mucous cells population. Based on these findings, in the present case, a diagnosis of low grade central mucoepidermoid carcinoma was established.

Central mucoepidermoid carcinoma should be distinguished from various pathological entities, like residual cyst, chronic suppurative osteomyelitis, dentigerous cyst, odontogenic keratocyst, aneurysmal bone cyst, traumatic bone cyst, ameloblastoma, central giant cell granuloma and malignancies. Though there exist several systems to diagnose and stage this neoplasm, histopathological diagnosis remains the universally accepted golden standard.

Metastases are reported in 9\% of CMEC, mainly to the regional lymph nodes. Nodal metastases have been described from 1 to 24 years after the time of initial management. ${ }^{6}$ The widely practiced main treatment for CMEC is wide local excision with sectional or radical neck dissection in case of cervical involvement. Cervical nodal involvement was ruled out in our case. Documented recurrence rate for radical excision is $13 \% .^{6}$ The present case underwent a posterior enblock resection with no neck dissection. The histopathological findings of the excisional specimen confirmed the diagnosis of low grade CMEC. Prognosis is difficult to evaluate due to the inadequacy of the staging and the disparity of treatment reported in the literature, whereas a well-differentiated, low-grade tumor without perineural invasion and with tumor-free margin indicates a good prognosis. ${ }^{11}$ The CMEC that are graded in the intermediate to high grade range imply a worse prognosis than low-grade tumors. The presented case has been disease free for past 14 months.

\section{REFERENCES}

1. Azevedo RS, de Almeida OP, Kowalski LP, Pires FR. Comparative cytokeratin expression in the different cell types of salivary gland mucoepidermoid carcinoma. Head and Neck Pathol 2008;2(4):257-264.

2. Bansal A, Shetty DC, Rai HC, Singh HP. Primary intraosseous mucoepidermoid carcinoma of maxilla: a rare occurrence. E-Journal of Dentistry 2011;1(1):14-17.

3. Barnes L. Surgical pathology of the head and neck. 3rd ed. Informa healthcare. Diseases of Salivary Glands. p. 546-552.

4. Barnes L, Eveson J, Reichart P, Sidransky D. Pathology and genetics of head and neck tumours. WHO classification of tumours. Tumours of Salivary Glands. Lyon: IARC Press; 2005. p. 219-220.

5. Tucci R, Antonio LFM, de Carvalhosa AA, de Sousa Castro $\mathrm{PH}$, Nunes FD, Santos Pinto DD Jr. Central mucoepidermoid carcinoma: report of a case with 11 years' evolution and peculiar macroscopical and clinical characteristics. Med Oral Pathol Oral Cir Bucal 2009 Jun 1;14(6):E283-E286.

6. Maremonti P, Califano L, Mangone GM, Zupi A, Guida C. Intraosseous mucoepidermoid carcinoma: report of a longterm evolution case. Oral Oncology 2001;37(1):110-113.

7. Waldron CA, Mustoe TA. Primary intraosseous carcinoma of mandible with probable origin in an odontogenic cyst. Oral Surg Oral Med Oral Pathol 1989;67(6):716-724.

8. Varma S, Shameena PM, Sudha S, Nair RG, Varghese IV. Clear cell variant of intraosseous mucoepidermoid carcinoma: report of a rare entity. J Oral Maxillofac Pathol 2012;16(1):141-144.

9. Alexander RW, Dupuis RH, Holton H. Central mucoepidermoid tumour (carcinoma) of the mandible. J Oral Surg 1974; 32(7):541-547.

10. Browand BC, Waldron CA. Central mucoepidermoid tumours of the jaws. Oral Surg Oral Med Oral Pathol 1975;40(5):631-643.

11. Li Y, Li LJ, Huang J, Han B, Pan J. Central malignant salivary gland tumours of the jaw: retrospective clinical analysis of 22 cases. J Oral Maxillofac Surg 2008;66(11):2247-2253. 